\title{
Analysis of the use of a robot to improve social skills in children with autism spectrum disorder
}

\author{
Carlos Torturella Valadão*, Christiane Goulart, Hamilton Rivera, Eliete Caldeira, \\ Teodiano Freire Bastos Filho, Anselmo Frizera-Neto, Ricardo Carelli
}

\begin{abstract}
Introduction: Autism Spectrum Disorder is a set of developmental disorders that imply in poor social skills, lack of interest in activities and interaction with people. Treatments rely on teaching social skills and in such therapies robotics may offer aid. This work is a pilot study, which aims to show the development and usage of a ludic mobile robot for stimulating social skills in ASD children. Methods: A mobile robot with a special costume and a monitor to display multimedia contents was designed to interact with ASD children. A mediator controls the robot's movements in a room prepared for interactive sessions. Sessions are recorded to assess the following social skills: eye gazing, touching the robot and imitating the mediator. The interaction is evaluated using the Goal Attainment Scale and Likert scale. Ten children were evaluated (50\% with ASD), using as inclusion criteria children with age 7-8, without use of medication, and without tendency to aggression or stereotyped movements. Results: It was observed that the ASD group touched the robot about twice more in average than the control group (CG). They also looked away and imitated the mediator in a quite similar way as the CG, and showed extra social skills (verbal and non-verbal communication). These results are considered an advance in terms of improvement of social skills in ASD children. Conclusions: Our studies indicate that the robot stimulated social skills in $4 / 5$ of the ASD children, which shows that its concepts are useful to improve socialization and quality of life.
\end{abstract}

Keywords: Autism spectrum disorder, Social skills, Social robots, Assistive technology.

\section{Introduction}

Children with Autism Spectrum Disorder (ASD) may lack social and communication abilities, which are fundamental for quality of life and interaction with other people (Kim et al., 2013). These children usually have difficulties in displaying and perceiving emotions and social clues, a situation that complicates even more their lack of communication (Duquette et al., 2008; Kim et al., 2013; Scassellati et al., 2012). The aetiology of ASD remains undefined and studies show that this condition may have multifactorial causes such as genetics and environment (Rutter, 2005). The ASD comprehends the classic autism, the Asperger Syndrome and the PDD-NOS (Pervasive Developmental Disorder Not Otherwise Specified) (Brasil, 2013; Lord et al., 2000).

Considering its spectrum nature, ASD appears in different levels and symptoms, although the main aspect, remarkable in all kinds of ASD, is the lack of socialization and communication skills. In addition, individuals affected by ASD have difficulties in understanding and expressing emotions, engaging in eye contact, joining interactive activities (imitation and joint attention), among other social-like behaviours, and sensitivity to physical contact (touching) (Scassellati et al., 2012). In the Asperger Syndrome, there is a normal intellectual developing (Lord et al., 2000), with paired language and intellect, but these children also present social interaction deficits and restricted interests and behaviours (Klin, 2006).

ASD epidemiology varies from $0.62 \%$ to $2.64 \%$ of the population, values that change due to the techniques and data used to diagnose autism (Elsabbagh et al., 2012; Leventhal et al., 2013). According to the Autism Society (Autism..., 2016), the Central of Disease Control and Prevention (Centers..., 2013) estimates that one in each 68 children is born with autism in the USA $(1.47 \%)$, where the autistic population is more than 3.5 million people. The Diagnostic and Statistical Manual of Mental Disorders estimates that an average of $1 \%$ of the world population has autism spectrum disorder (American..., 2013). Some statistics shows the prevalence of autism worldwide: in France, it is estimated $0.67 \%$ of the population has ASD (Autism..., 2012); in Canada, 0.68\% (Norris et al., 2006); in Singapore, 1\% (Autism..., 2013); in the UK, 1.1\% (The National..., 2015); in Japan, 1.61\% 
(Honda et al., 2005); and in South Korea, 2.64\% (Leventhal et al., 2013).

Still regarding the epidemiology worldwide, the gender ratio of children diagnosed with ASD are of 4.2 boys for each girl, which shows a higher prevalence in male population (Fombonne, 2009). In Brazil the epidemiologic studies are scarce, with an estimate of 500,000 people with autism $(0.29 \%)$, based on the 2000 Census (Brasil, 2013). However, there is no current official numbers of ASD people in Brazil. In addition, the diagnostics of autism is not simple and can be based on several factors and biological data, such as clinical, molecular and neuroimaging findings, among others (Rossignol and Frye, 2012).

Children affected by ASD can rely on behavioural treatments that can help them to live a better life by teaching them social skills. Studies, such as (Scassellati et al., 2012), suggest that such intervention therapies should start as early as possible to achieve its maximum efficiency. The treatment is based on stimulating the child to interact with other people and using several tools and strategies, such as toys and activities that resemble games. It is usual for children to receive different stimuli, for example different kind of sound (Lamas et al., 2009), although most of these studies focus on social and communication skills (Scassellati et al., 2012). Currently, several studies try to find ways to bring new stimuli to those children, in order to make them achieve better outcomes in the cognitive and social development. For example, robots and games are used to stimulate the development of social skills, such as verbal, imitation and tactile sensitivity (Cabibihan et al., 2013; Kim et al., 2013), in order to investigate how these children react to different kinds of stimuli and how these stimuli could be useful for therapies and treatments (Duquette et al., 2008; Michaud et al., 2003).

Robots able to stimulate social and cognitive abilities in ASD children can be classified into anthropomorphic, non-anthropomorphic and nonbiomimetic (Cabibihan et al., 2013; Scassellati et al., 2012). The first category resembles some human features in its appearance. The second one does not resemble human features, but biological features, such as animals. Finally, the third category is composed of robots, whose appearances do not resemble any biological creature. Examples of those robots are PLEO, Keepon and Paro (non-anthropomorphic) (Kim et al., 2013; Kozima et al., 2009; Scassellati et al., 2012; Wada et al., 2004), KASPAR, ROBOTA, NAO (anthropomorphic) (Cabibihan et al., 2013; Dautenhahn, 2003; Robins and Dautenhahn, 2014) and Pekee and Roball (non-biomimetic) (Michaud et al., 2003; Salter et al., 2006). All of them are used in autism therapy, trying to assist children in demonstrating and perceiving emotions, as well as interacting with others.
In the field of robotics, these devices are known as social-assistive robots, which is addressed to help people to express emotions and offer them the opportunity of human-robot interaction (Scassellati et al., 2012).

In fact, ASD children may react better to robots, due to its predictability, in contrast with the unpredictable nature of humans (Cabibihan et al., 2013; Duquette et al., 2008). Thus, it is possible to design a robot to interact in different ways with these children and give its architecture a ludic aspect, therefore, providing the robot the possibility of offering a pedagogical and developmental aid to these children (Duquette et al., 2008; Kim et al., 2013; Kozima et al., 2009). An example is a toy-like robotic platform named ROBUS (ROBot of Université de Sherbrooke), used in research with ASD in Canada (Michaud and Clavet, 2001). Other examples of robotic aid in therapies of ASD children is shown in researches (Cabibihan et al., 2013; Kim et al., 2013; Kozima et al., 2009; Robins and Dautenhahn, 2014; Scassellati et al., 2012).

This paper describes a research that employs a robot to stimulate social skills in ASD children, promoting eye gaze, touch, and imitation, besides interaction with people. The robot used is called MARIA (acronym for "Mobile Automatic Robot for Interaction with Autistics") and this work is a pilot study with five ASD children and five children from a control group, CG (without ASD), based on interactive session with the robot MARIA. In such sessions, the children's behaviours are analysed, and their social skills and quality of child-robot interaction are measured through a quantitative scale (GAS) and a questionnaire using Likert scale. A search conducted in 2016 in SCOPUS, Web of Science and IEEE Xplore databases for "autism spectrum disorder", "social robots" and "assistive technology" resulted in no other work with similar approach related to ASD children interacting with robots, and no other work was found with similar features as the robot here presented: protocol including a robot self-presentation; robot with a mix style of human and non-biomimetic appearance; the way of evaluating the results, including questionnaires and scales, in addition to specific aspects related to socialization, such as number of times that the children gaze the robot, touch the robot, and imitate the mediator.

\section{Methods}

\section{Volunteers}

The volunteers of this study were five ASD children and five without ASD (control group), with ages ranging from 7 to 8 years old. The ASD children are with AMAES (acronym in Portuguese 
for "Association of Friends of Autistics of Espírito Santo"). The children from the control group are with EMEF-UFES (Municipal Elementary School of Vitoria at Federal University of Espírito Santo). To the ASD children attend the sessions, the inclusion criteria used were: children should have an ASD diagnostic made by a physician. On the other hand, the exclusion criteria were: children should not have experienced any traumatic episode or phobias, nor neurological diseases simultaneously with ASD or other syndromes that affect significantly the motor and behavioural development; expressive stereotyped movements; constant tendency to aggressiveness; or use of medication that affects the neurological system.

These exclusion criteria are important, since this is a pilot study and the features aforementioned could affect directly the analysis that are made during the experiments, as most of the ASD children take medications in a regular basis, which can alter significantly their behaviours. Besides, most of them present stereotype movements, tendency to aggression or agitation, fact that notably reduces the available number of volunteers. This turns the volunteer selection extremely difficult, adding the fact some parents do not accept their children take part on the sessions or simply they do not show up in the sessions.

The volunteer ASD children were diagnosed by medical professionals before entering in AMAES and were under psychological, speech and/or pedagogical therapy in such association. Before selecting the children, an extensive study and analysis together with the institutional pedagogues were made in order to determine which children could participate. After making the analysis with the pedagogues, we were able to select five ASD children to take part of the experiments whose details are described in the list below:

- V1: Female, 7 years old. Diagnosed with autism on 03/02/2011.

- V2: Male, 8 years old. Diagnosed with autism on $06 / 20 / 2011$.

- V3: Male, 8 years old. Diagnosed with autism on $05 / 07 / 2012$.

- V4: Male, 7 years old. Diagnosed with autism on $08 / 14 / 2012$.

- V5: Male, 7 years old. Diagnostic defined in $01 / 2012$.

All parents (from both groups) signed a consent form, previously approved by the Ethical Committee of the Federal University of Espírito Santo $(\# 1,101,769)$. The parents, caretakers, family members, and/or legal guardians were invited and were present to watch the experimental sessions.

This manuscript presents a proof-of-concept. Therefore, the authors aim to extract valuable information while aiming at a smaller group (10 subjects in total, with $50 \%$ being ASD children) when compared with more complex clinical trials. Such conduct is quite common in early stages of validation of a prototype. In fact, works, such as (Robins et al., 2004; Shamsuddin et al., 2012; Wainer et al., 2014), use smaller number of volunteers to make a proof-of-concept. The analysis made using the metric scales, which will be further explained, brings precious and important information, even with a small sample. Therefore, it is possible to evaluate the robotic system (explained in the following section) as a tool for applications in therapies with children with ASD and, then, showing that the robot is useful to promote child-robot and child-mediator interaction.

\section{Robotic system}

The methodology followed in this study was based on customizing a mobile robot, in order to give it a playful and toy-like appearance to interact with the children, stimulating their social skills, such as eye gaze, touch, and imitation, as those features usually are remarkably faulty in ASD children. Thus, taking into account the potential interaction aid that robots can offer to these children, the robot MARIA was designed in the Federal University of Espirito Santo (UFES), Brazil. An important aspect of the robot design is that it has a child-size height, which means the volunteers from both groups would interact with a robot with their similar height. Added to the size feature, the robot MARIA is a mobile robot, which differs from several robots presented in the literature that do not present mobility, such as (Kim et al., 2013; Kozima et al., 2009; Wainer et al., 2014). To develop the robot MARIA, some guidelines were used: the balance between human and robot (mechanical) style followed the recommendations found presented in the work (Giullian et al., 2010). In addition, the colourful aspect was taken into consideration, since it has great importance as shown in (Paron-Wildes, 2005). The robot features, further explained, were designed to maximize the interaction potential between the robot and the child. In addition to the robot shape itself, moving objects also catches the attention of children with ASD, thus, mobility is an another feature incorporated to the robot MARIA (Cabibihan et al., 2013).

To assembly this robot, a mobile platform was used, which was complemented by other accessories. The devices used in the robot MARIA are: (1) Pioneer 
3-DX differential drive mobile robot that allows the robot MARIA movements. It has three wheels, one free and two other motor wheels, and its kinematics is differential with non-holonomic constraints; (2) 12" monitor used to display animations; (3) Sound speakers used to emit sounds of the animations; (4) Internal notebook used to control the display and speakers; (5) Wi-Fi link to allow the internal computer connection to the master computer through VNC (Virtual Network Computing - a protocol designed to allow accessing a computer through network using graphical interface, as if the user were in front of the real computer) via Wi-Fi connection.

To hide the electronics and to make the robot friendlier, a costume was designed using soft fibreboard, colourful fluorescent papers, and ethylene-vinyl acetate foam (EVA). The costume gives a ludic shape to the robot, in order to turn the robot more attractive to the children. MARIA costume has human female features (eyes, nose, mouth, wig and eyelashes), stylized into a robotic-toy style, thus featuring a mix of anthropomorphic and non-biomimetic appearance. Figure 1 shows MARIA and a schematic diagram of the system functioning. The robot and the master computer (controls both the internal robot computer and the embedded robot computer; the embedded computer is actually a notebook that is on the robot and has no direct connection with the robot, only with the display and sound speakers) are connected to the router and, therefore, the master computer is able to control, send, and receive information from the robot. The monitor is connected directly to the robot's computer (embedded notebook) and is indirectly controlled by the master computer All these connections are made using a router and wireless connection. The robot functioning is shown in Figure 1a and the robot image is displayed in Figure $1 b$.

The robot MARIA, specially developed for social interaction with ASD children, has some remarkable features, compared to others in literature. First, most of the robots presented in the literature are smaller than the children, such as NAO, KASPAR, KEEPON, PLEO, ROBUS (Anzalone et al., 2014; Duquette et al., 2008; Kozima et al., 2009; Robins and Dautenhahn, 2014). MARIA has the average height of the volunteers $(1.35 \mathrm{~m})$, which, according to the literature (Robins et al., 2006), makes the interaction easier. In addition, most of the robots used to help ASD children are static and neither use videos to stimuli them nor make its self-presentation before starting the experiments. These features distinguish our work from the others presented in the literature. Table 1 shows a comparison between the robots and the experiments conducted with those robots and the robot MARIA, making clear that MARIA is an innovative robot, with elements no previously addressed.

MARIA is a child-size mobile robot with similar height of the volunteers and with multimedia devices, besides including self-presentation and other behaviours, which will be further explained. Regarding the number of children, the hypothesis we want to prove is if a mobile robot with the similar height and with self-presentation could promote an interaction in a low number of sessions without any previous training from the child. The main idea of this work is to make a proof-of-concept application, in order to know whether the robot MARIA (child-size robot) with multimedia content can make ASD children develop their social skills. As shown in some works, such as (Giullian et al., 2010), the robot appearance influences directly in the children's behaviour and reactions. Mobile objects and colourful aspects are also important aspects for children with ASD, regarding the environment, as shown in (Paron-Wildes, 2005), where the author says $85 \%$ of the children with ASD can see the colours in a more vibrant intensity.

In addition, the research conducted in (Giullian et al., 2010) suggests some guidelines to make a robot that will be visually attractive and functional to both children and therapist. There, the authors discuss the idea of using a child-size robot is positive, since it may encourage the children to interact with it. In addition, the balanced similarity with human and robot, i.e., not being so human-like and, at same time, not being so mechanical-like, makes the robot more attractive to the children. If it looks too human, it may lead the children into fear and/or lack of interest, while if it looks too mechanical, the child would be more interested in examining it, instead of interacting with it (Giullian et al., 2010). Summarizing, the robot should have the children's height to allow eye-level interaction and, at the same time, it should look a mix-style between human and mechanical structure to make the children interested in the robot. In (Giullian et al., 2010), it is also commented the importance of the robot having a predefined choreography in its memory, such as the self-presentation, which is in the section "Experimental sessions". Complementing those previous guidelines, the robot shape, colours, and size were also defined according to suggestion of caretaker and health professionals from AMAES and children's parents. Thus, one of the innovations of this work is to use the robot with these whole guidelines regarding height, size, and colours. 

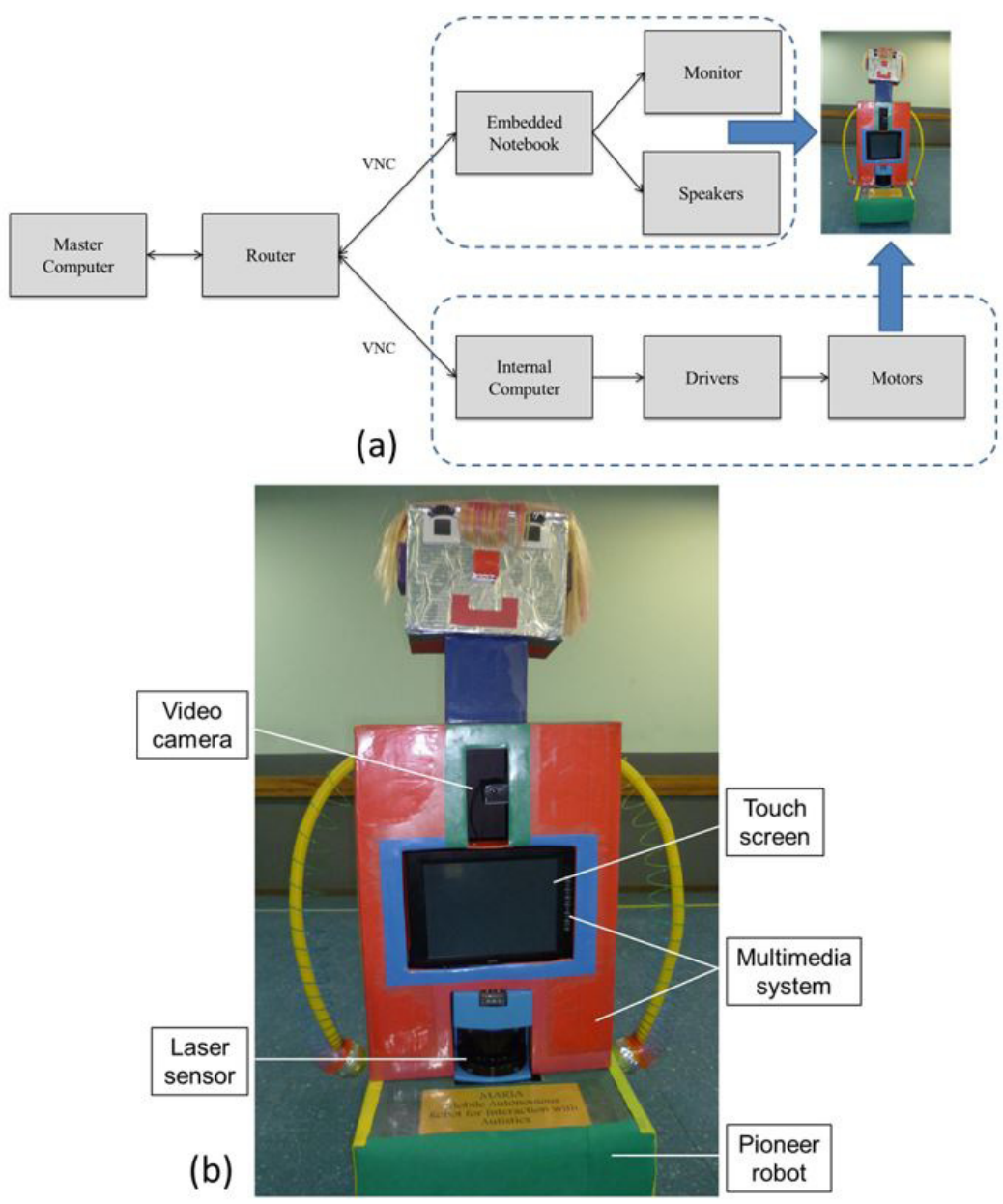

Figure 1. Schematic of the robot operation and details of the robot structure.

This helps the child getting used to the robot and also allows the therapist not worry with the robot and focus on the therapy instead on the robot functioning. It is important to emphasize the children should not have any previous contact with the robot before the tests, thus making the self-presentation essential to make the child comfortable and willing to play with the robot.

Their suggestions led us to build the robot with the average 7-8 years old children height and with a plenty number of different colours and textures, making it more attractive to the children. This may help the interaction of the children with other children and they can see the robot as a friend. In addition, the self-presentation, detailed in "Experimental sessions," Phase 1, is essential to create a sense of safety in the child that interacts with the robot. The self-presentation is also another innovation of this work.
Summarizing, the robot aspect and the Phase 1 of the experiments were important to make the children, who have never seen the robot before, get used to it. Afterwards, in the next part of the experiment, they were more confident in interacting with the robot.

\section{Experimental sessions}

ASD children have difficulty in processing large number of information and stimuli as it may overload them, which may lead them not to behave naturally. Therefore, the experiments need a simple setup and should not be complex, otherwise their natural behaviour towards the robot could not be analysed. Thus, the experiments conducted were not complex, and as well as not easy for the ASD children, in order to provide significant and important information regarding their behaviours and whether they interact with the robot. In addition, for not overloading the children, the experiments were split into two distinct phases: 
Table 1. Comparison among works of human robot interaction for ASD children.

\begin{tabular}{|c|c|c|c|}
\hline Reference & Robot & $\mathbf{N}$ & Interaction with the robot \\
\hline (Wainer et al., 2014) & KASPAR & $N=6$ & $\begin{array}{l}\text { The robot worked as a mediator helping children interacting } \\
\text { with each other in a triadic (with robot) interaction, while } \\
\text { playing a game, and with a dyadic (between two children } \\
\text { only), after having the triadic experience. Therefore, the robot } \\
\text { helped the interaction between the children. }\end{array}$ \\
\hline (Shamsuddin et al., 2012) & NAO & $N=1$ & $\begin{array}{l}\text { Robot NAO helped to initiate and support interaction with the } \\
\text { child. }\end{array}$ \\
\hline (Kim et al., 2013) & PLEO & $\mathrm{N}=24$ & $\begin{array}{l}\text { Robot could help children in scholar age to improve the } \\
\text { interaction and verbalization more than computer games or } \\
\text { other people. In addition, the robot could help the children to } \\
\text { interact with other humans. }\end{array}$ \\
\hline (Kozima et al., 2009) & KEEPON & $\begin{array}{l}\text { ASD }(\mathrm{N}=3) \\
\mathrm{CG}(\mathrm{N}=25)\end{array}$ & $\begin{array}{l}\text { Children felt interest in Keepon, enjoying the dyadic, } \\
\text { interaction with the robot and even a triadic interaction. } \\
\text { Although Keepon is a complex robot, the understanding of } \\
\text { how to interact with it was simple and made the children not } \\
\text { getting boring or overwhelmed, thus, enjoying the interaction } \\
\text { with the robot. }\end{array}$ \\
\hline (Robins et al., 2004) & ROBOTA & $\mathrm{N}=4$ & $\begin{array}{l}\text { It is a doll-like robot and the children use this robot as a } \\
\text { mediator and object to promote share attention for their } \\
\text { interactions with teachers. Throughout the time, the children } \\
\text { went more comfortable with the robot and seek it to interact } \\
\text { and share experience with the robot and with the caregiver. }\end{array}$ \\
\hline (Simut et al., 2015) & PROBO & $\mathrm{N}=30$ & $\begin{array}{l}\text { This robot did not work as a social mediator, but had similar } \\
\text { social interaction for ASD children as other humans have. } \\
\text { The eye-gazing aspect called more attention from the autistic } \\
\text { children, but the other variables (joint attention, verbal } \\
\text { utterance, positive affect, among others) did not have great } \\
\text { difference. }\end{array}$ \\
\hline This paper & MARIA & $\begin{array}{l}\operatorname{ASD}(\mathrm{N}=5) \\
\mathrm{CG}(\mathrm{N}=5)\end{array}$ & $\begin{array}{l}\text { This robot has multimedia devices and it is of the same height } \\
\text { of the volunteers. Besides, it had a self-presentation mode } \\
\text { (one of the phases of the experiments) that contributes a lot } \\
\text { for a first child-robot contact. The results of the experiments, } \\
\text { which were positive, are explained further in the next section. } \\
\text { The size is a differential of this robot, together with the self- } \\
\text { presentation behaviour that helps the child get used with the } \\
\text { robot before directly interact with it. This creates an emotional } \\
\text { bond between the child and the robot, making him/her more } \\
\text { confident in interacting with it. Some children who apparent } \\
\text { fear in this first moment, could get more relaxed and confident } \\
\text { after the self-presentation, which shows the importance of this } \\
\text { part of the test. In addition, the robot presented a balanced } \\
\text { human-robot mixed style to attract the child attention and not } \\
\text { to overload them with much information. }\end{array}$ \\
\hline
\end{tabular}

- Phase 1 (Robot self-presentation): The child sits comfortably in a rug, and the robot initially is covered with a fabric. The session begins when the mediators take out the fabric (that covers the robot) and, in sequence, two animations are displayed. At the same time, the robot starts to move in a predefined set of movements at a maximum of $0.2 \mathrm{~m} / \mathrm{s}$ and $20 \%$ s. In this phase, it is counted how many times the child looks away the robot. If the child looks at the robot most of the time, it is considered he/she is keeping the attention to the robot. The robot movements are shown in Figure 2. This phase finishes at the end of the second animation. Phase 1 is important to create a bond between the robot and the child and to prepare the child to have a better interaction (Phase 2). The robot introduction and self-presentation is used with the goal to help children feeling more confident and comfortable towards the robot, which is an important issue addressed in this work. If the child interacted directly with the robot, without any previous presentation, the chances of fearing the robot would increase. Thus, in this phase, the robot moves towards the child exhibiting the animations and, in some parts of its movement, the robot spins 
clockwise and counter-clockwise (as shown in Figure 2) to allow the children to see the whole costume (all its colours and shapes).

- Phase 2 (Interaction invitation): this phase starts when the mediators invite the child to interact with the robot. In the first part of Phase 2, the robot is kept detained. The child is then encouraged to stand up from the rug, in order to touch the robot and look it closely (its colours and shapes). In the second part of Phase 2, the mediators invite the child to play with the robot. The mediators exemplify a game to the child, which consists of two movements: going towards the robot and going away from the robot. The robot starts moving (remotely commanded by the other mediator) and, then, the child is encouraged to imitate the mediator's game. Each time the child repeats a mediator's movement, it is considered one imitation. In this phase, touching and imitation are the two features counted for evaluating the interaction level of the experiment.
The session is ended when the duration has already reached the maximum of $40 \mathrm{~min}$ or if the child presents tiredness. When the session ends, the robot is stopped and all the system is shut down. The time is an important factor to standardize all the sessions, creating a pattern that allows the comparison of interactions per minute for the numerical analysis, which is presented further. All the sessions are video-recorded to further detailed analysis of the child robot interaction.

\section{Analysis of the child-robot interactions}

The analysis of the child-robot interaction was obtained from the two phases of experiments, where the social skills of the child-robot interaction were evaluated. In the first phase, the social skill assessed was the eye gaze, by counting the number of times the children looked away the robot. In the second phase, the social skills assessed were touch and imitation, by counting the number of times the child touched the robot and imitated the mediators. The evaluations were made through the analysis of video recordings. The total video recording time (including both children

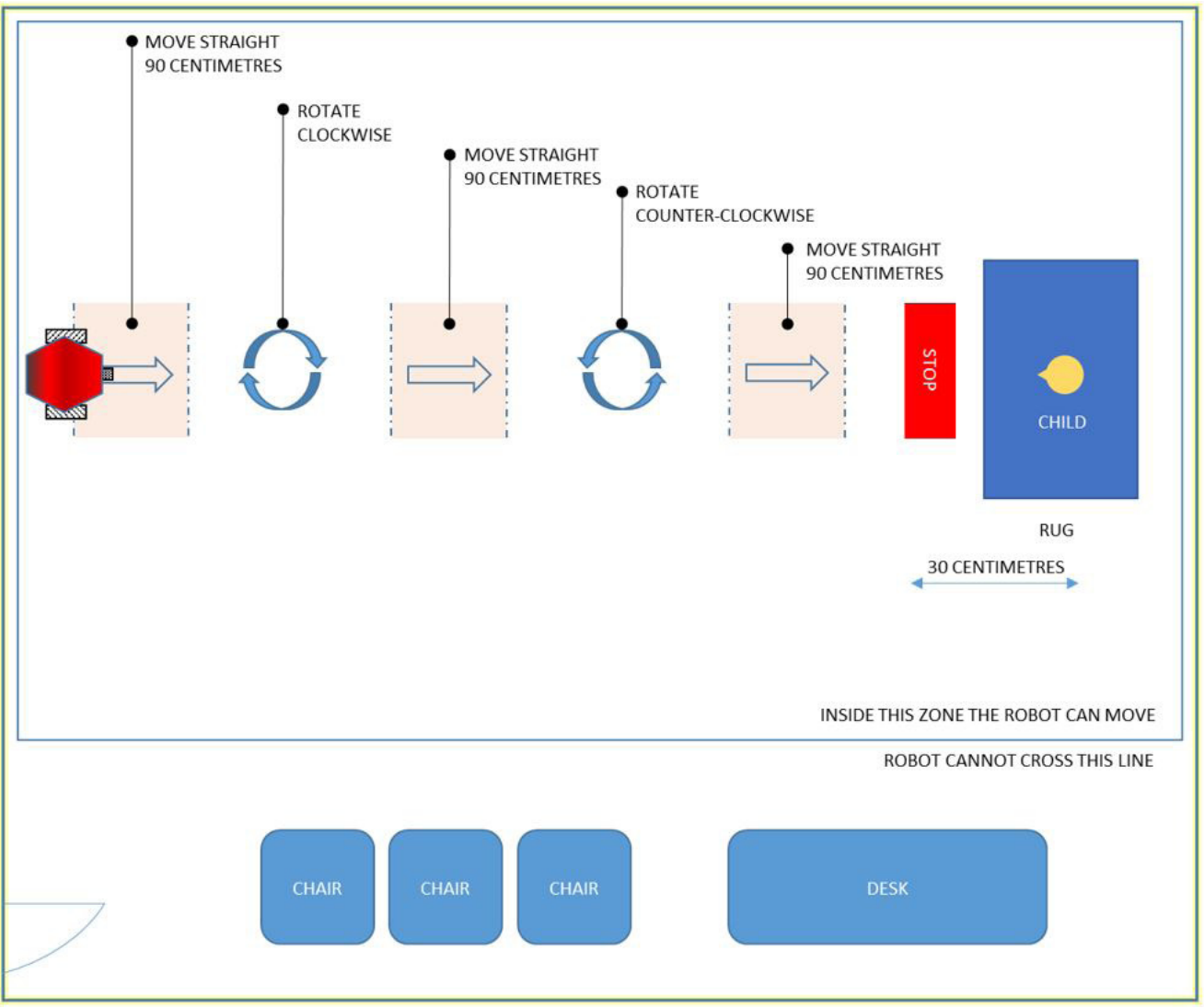

Figure 2. Floor plant of the session room and robot's movements of Phase 1. 
with and without ASD) was 9 hours 34 minutes and 22 seconds, taken from two different cameras.

\section{Observational data}

Based on the video recording, we took some observational notes and evaluated some extra social skills of the ASD children. Table 2 contains some general notes about the children's reactions during the sessions, such as communication, different forms of imitation and interaction with the mediators and the robot.

Following, comparisons between the ASD and control groups were made, through a frequency analysis of the social skills (look away the robot, touch the robot and imitate the mediator). The results of these comparisons are presented in Figure 3a. It shows that the social demonstrations of looking away the robot were present in all children. In ASD children, these demonstrations were associated with the random eye contact break or joint attention of these children with their parents or mediator, which was considered positive. In Figure $3 b$ boxplots compare the social skills performed by both children groups.

Figure $3 \mathrm{~b}$ demonstrates that the median values related to looking away the robot (2.59 vs. 2.73 for ASD group and control group, i.e., children without ASD, respectively) and imitation ( 0.2 vs. 0.18 ) are very similar in both groups. This indicates the robot is able to stimulate these social skills in ASD children that performed them similarly to the control group children. For the tactile skills, the ASD children performed a higher number per minute when compared with the control group (median of 2.97 for the ASD group vs. median of 0.76 for the $\mathrm{CG}$ group).

\section{Questionnaire based on Likert scale}

In order to measure the extra behaviours or different reactions of the children towards the robot, we used a questionnaire based on Likert scale (Bartneck et al., 2009). This questionnaire was, actually, a set of six sentences related to the child's behaviour presented during the sessions. The intensity of the occurrences of such sentences was specified in the following

Table 2. Notes about the sessions with ASD children (V1-V5).

The animations exhibited during the Phase 1 attracted the attention and the interest of the child. When the robot
and the animations stopped, she was encouraged to stand up in order to look the robot closely, touch it, and play
with it (Phase 2). However, she showed a little fear, presenting resistance to interact with the robot.
During the exhibition of the animations (Phase 1), he liked the videos, since he exhibited happy facial expressions.
In the Phase 2, he responded to the mediator's commands relative to touch the robot, look it closely, and play
with it. He repeated several times the game of approaching and moving away performed with the robot, prior
demonstrated by the mediator. He interacted with the robot and the mediator at the same time, in which both held
the hands of the robot and walked together. When asked, he pointed and answered the name of the parts of the
robot's body. Details of this experiment can be visualized at Valadao (2016). The shape of the robot was crucial
in this test, since in one moment the child used one of the robot arms as a "microphone" and started singing.
That shows this child found new and particular ways of interacting with the robot.
While the robot moved in the Phase 1, he was a little afraid, trying to go away. However, when he was encouraged by the mediator, he remained seated on the rug. He understood the mediator's commands to stand up in order to interact with the robot (Phase 2). Initially, he chose to look it away. Further, he interacted with the robot encouraged by the mediator and performed the commands holding the mediator's arms and hands. He also

V3 established physical contact with another mediator, when she touched and played with the robot. Besides, he walked with the robot and the mediator, and both held the robot's hands. The child indicated the directions that the robot should move, through pointing. The child liked to play with the robot, since he presented happy facial expressions. Particularly, this child presents difficulties in verbal communication, nonetheless, when asked, he answered the name of some parts of the robot's face. This fact rejoiced his grandmother who watched the session.

When the robot started to move (Phase 1), the child demonstrated fear, calling his mother. She and the mediator encouraged him to look at the robot and to remain seated on the rug. During the display of the first animation, he demonstrated to like it, looking at his mother, as a joint engagement. During the second animation, he said that he

V4 did not like cartoons. In Phase 2, during the interaction with the robot, he touched the robot and, when asked, he answered the name of all the parts of the robot's body and colours. Initially, he played with the robot, holding the mediator's hand. Besides, he walked with the robot and the mediator, and both held the robot's hands. The child indicated the directions that the robot should move, through his hands and the speech.

During the Phase 1, the child was very curious and interested, looking at the robot and watching the animations. In the Phase 2, he performed the commands of the mediator to stand up in order to interact with the robot. Initially, he looked at the robot at distance. Nevertheless, encouraged by the mediator, he interacted by touching the robot,

V5 looking at it closely, walking with it, and holding its hand. He also interacted with the mediator, holding her hands occasionally, and imitating her during the game of approaching and moving away performed with the robot. Besides, he imitated the mediator's movements of squatting and lifting. Although the child does not speak, he babbled, appointed to the robot and to the directions where the robot should move, and he demonstrating he liked the robot, due to his facial expressions of joy. 


\section{Social Abilities Demonstration Frequency}
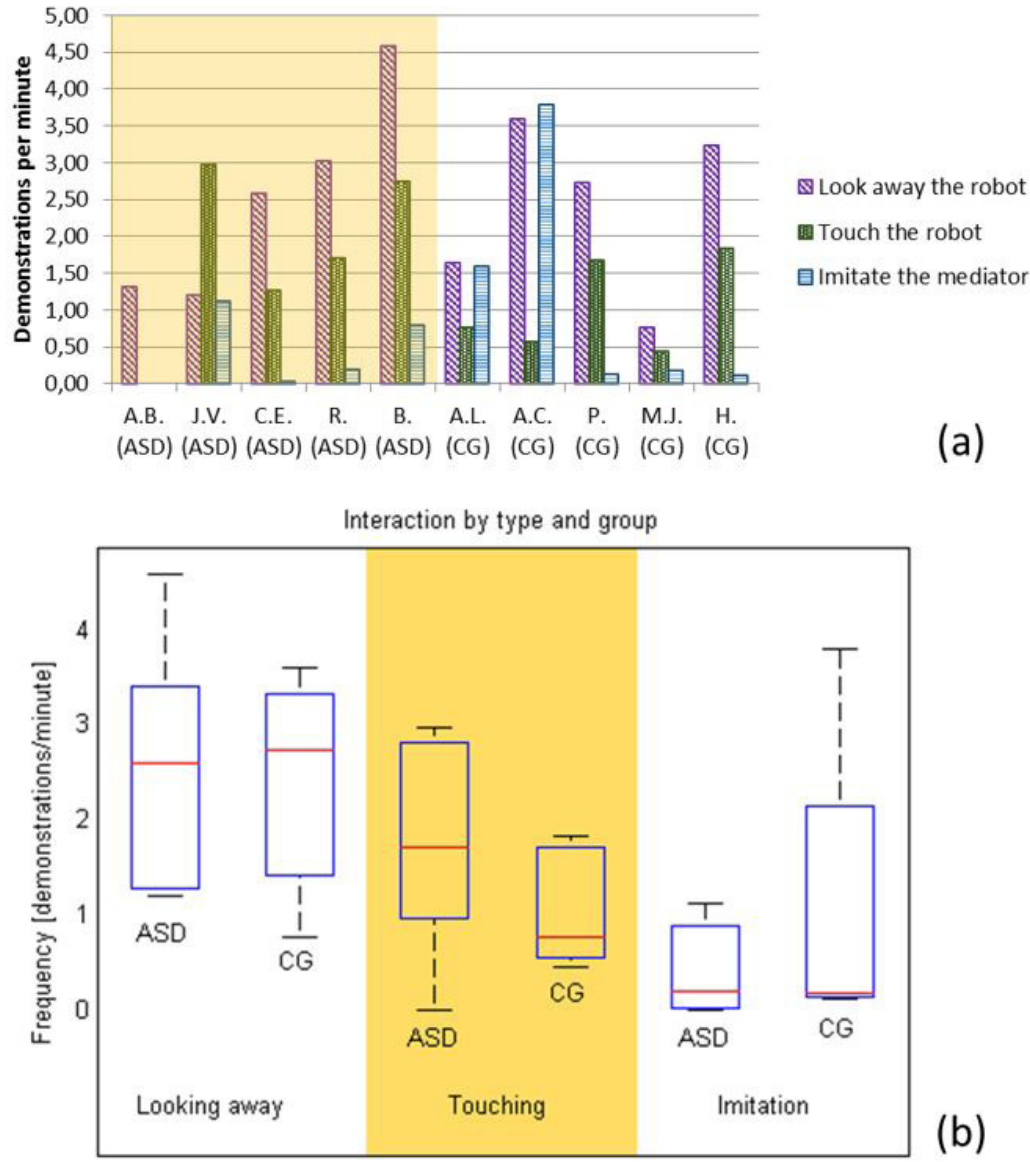

(b)

ASD vs Control Group

Figure 3. (a) Social skills frequency demonstrated by group and type, for ASD children and for the control group (CG); (b) Boxplots of social skills showing the behaviour in both groups.

way: "1 - Never", "2 - Rarely", "3 - Occasionally", "4 - Frequently" or "5 - Always" for the questionnaire shown in Figure 4.

Through Figure 4, features such as verbal communication, emotional demonstration and interaction with other people were analysed. It is possible to infer that the robot did not bring negative emotions for the children in general (only for 1 out of 5), and most of the ASD children (3 out of 5) displayed excitement and happiness feelings when interacting with the robot.

\section{Goal Attainment Scale (GAS)}

The GAS method was used to verify the children skills, based on the video recording and observational data. The GAS method converts qualitative into quantitative data, allowing evaluating the success in achieving goals (Kiresuk and Sherman, 1968; Krasny-Pacini et al., 2013; Turner-Stokes, 2009). In this work, the goals defined for the GAS method were three: (1) Look at the robot: analysed in Phase 1. Look to the robot is related to eye contact, which is faulty in ASD children (Scassellati et al., 2012), as they usually have absent, reduced or atypical use of eye contact, which is featured as deficit of nonverbal communication and consequently impairs the social interaction (American..., 2013); (2) Touch the robot: a large number of ASD children have sensitivity to physical contact. This is a basic form of communication, being critical to typical physiological development in ASD children, and also help creating the bonding between the parents and the child (Costa et al., 2015; Knapp, 1978); and (3) Imitate the mediator: this ability is important to the development of cognitive, 
language and social skills and it is usually impaired in ASD children (Bekele et al., 2013; Ingersoll, 2012).

The challenge of this study is to verify if the robot is able to stimulate these skills and, at the same time, work as a tool that promote the interaction between the child and the mediator (imitation). It is important to emphasize that studies about child-robot interaction are still emerging in Brazil. The GAS method is here used as a way to assess that interaction, in which each goal of the interaction receives a score, according to how well the child achieves the defined goals. There is an expected standard level of task accomplishment that receives the score zero in the scale, which is the baseline. If the child accomplishes the tasks more effectively than the standard, the scores are higher and can be +1 or +2 , respectively "greater than expected" or "much greater than expected." On the other hand, if the tasks are considered badly accomplished, the scores received are negative, going from -1 down to -2 ("worse than expected" and "much worse than expected," respectively). Table 3 shows the expected goals and the respective scores to reach the goal.

GAS method has an equation that converts the goals scores into an overall score (T), which is shown in (1) (Krasny-Pacini et al., 2013).
$T=50+C_{x} \sum x_{i}$

where $C_{x}$ is the coefficient value for $x$ goals. Then, since we defined three goals, $\mathrm{C}$ value is 4.56 . The average score is 50 , since this is the value that would be reached if all the goals were achieved as expected. Figure 5 shows the results of the GAS method.

Although the overall average of the GAS method was over 50, the graph shows one child with ASD that presented a score under 50 (volunteer V1). On the other hand, all the other children had scores over 50, fact that represents a "better than expected result."

\section{Discussion}

A proof-of-concept of the robot can be achieved by analysing the experimental results, such as done in other works related to the use of robots to interact with children with ASD (Robins et al., 2004; Shamsuddin et al., 2012; Wainer et al., 2014). Therefore, although some metric scales were also used, the results brought valuable information by analysing the performance of each volunteer and evaluating the control group versus the autistic group. The main idea of the paper is to show the robot as a useful tool

\begin{tabular}{|l|l|c|c|c|c|c|}
\hline Statements & A.B. & J.V. & C.E. & R. & B. \\
\hline$\# 1$ & The child attended to the mediator's commands & 2 & 5 & 4 & 3 & 4 \\
\hline$\# 2$ & The child showed fear during the session & 5 & 1 & 3 & 3 & 2 \\
\hline$\# 3$ & The child felt repulsion by the robot & 5 & 1 & 2 & 3 & 1 \\
\hline$\# 4$ & The child demonstrated excitment & 1 & 3 & 4 & 2 & 4 \\
\hline$\# 5$ & The child demonstrated happiness & 1 & 4 & 5 & 2 & 5 \\
\hline$\# 6$ & The child communicated verbally & 3 & 3 & 2 & 4 & 1 \\
\hline
\end{tabular}

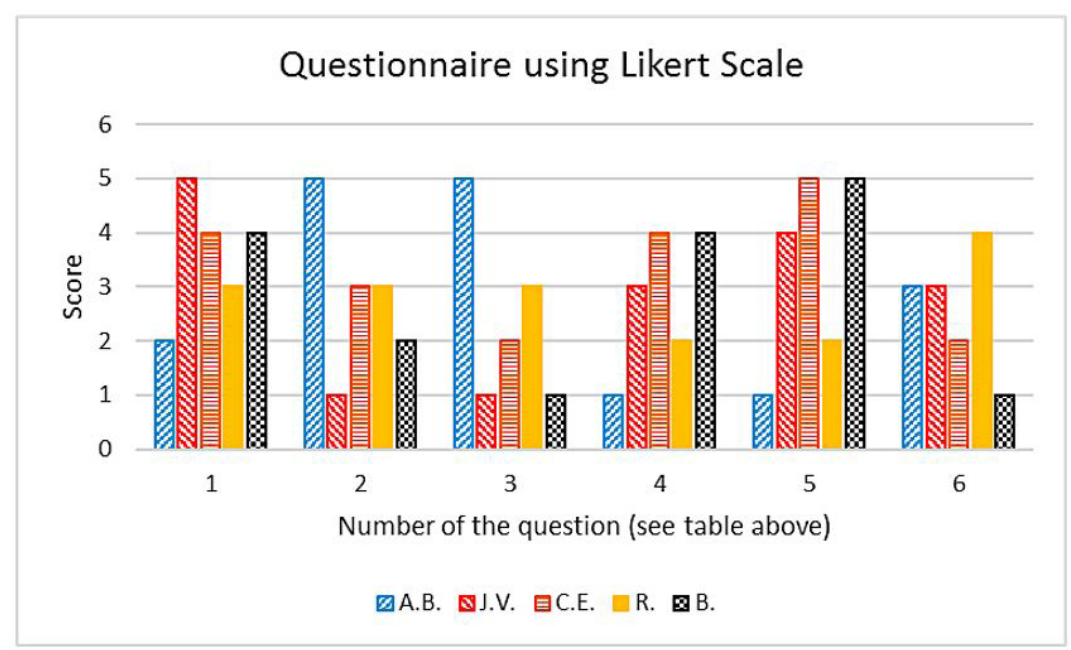

Figure 4. Results of the questionnaire based on the Likert scale for sessions for each child with ASD. 
for applications in therapies with children with ASD and, in addition, to demonstrate the children (both with and without autism) can interact comfortably with the robot.

The robot shape, size, colours and mobility are essential to perform the tests and to make the children with ASD feel comfortable with a robot of same average height (Giullian et al., 2010). In the literature, to our knowledge, there is no robot with such colours and size, which also takes into consideration the volunteer children's average height.

MARIA has a human-robot mixed style and its size is comparable with a typical 7-8 years old kid height (same age of the children who volunteered the tests). These aspects make difference in the results, since, in the literature, the robots usually are much smaller than the children, such as can be viewed in the works (Kim et al., 2013; Kozima et al., 2009; Wainer et al., 2014), shown in Table 1. In other words, the robot's size (especially the height) could either inhibit or make the child more comfortable. The interaction with MARIA by those children showed that not only they did not fear the robot, but they also socialized in a good way with MARIA through reactions such as presenting social abilities in a satisfactory way, staring the robot, touching it and imitating the mediator. In addition, no other work in the literature showed a robot with similar features of MARIA, especially in terms of height, multimedia devices, and self-presentation.
This makes our work novel and different from those conducted until now.

The sessions of this study were designed in a way that the Phase 1 (robot self-presentation) was used to make the child more comfortable with the robot, thus creating a sense of trusting and familiarity, with the children recognizing the robot as a non-threatening and interesting creature. Then, after Phase 1, it was observed that the children increased their interaction with the robot and mediators in Phase 2. In addition, the children could interact more freely and could even go beyond the commands given by the mediators while playing with the robot. They also expressed verbal and non-verbal communication with or without sense, indicating excitement during the interaction.

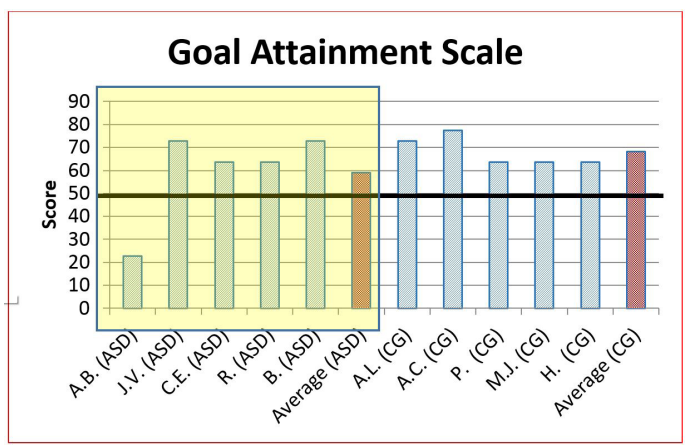

Figure 5. GAS scores for ASD children and from the control group (CG)

Table 3. Goal Achievement Scale (GAS) used to convert qualitative into quantitative data.

\begin{tabular}{|c|c|c|c|c|}
\hline \multicolumn{2}{|l|}{ GAS } & \multirow{2}{*}{$\begin{array}{c}\text { Phase } 1 \\
\text { Look at the robot }\end{array}$} & \multicolumn{2}{|r|}{ Phase 2} \\
\hline Predict Attainment & Score & & Touch the robot & Imitate the mediator \\
\hline $\begin{array}{l}\text { Most unfavourable } \\
\text { outcome }\end{array}$ & -2 & $\begin{array}{l}\text { Look at the robot in the } \\
\text { Phase } 1, \text { feel fear and } \\
\text { have no reaction. }\end{array}$ & $\begin{array}{l}\text { Stay away from the } \\
\text { robot and do not touch } \\
\text { it. }\end{array}$ & $\begin{array}{l}\text { Stay seated, even though the } \\
\text { mediator encourages him/her to } \\
\text { stand up in order to visualize the } \\
\text { robot closely and to play with it } \\
\text { as shown by the mediator. }\end{array}$ \\
\hline $\begin{array}{l}\text { Less than expected } \\
\text { outcome }\end{array}$ & -1 & $\begin{array}{l}\text { Look at the robot in the } \\
\text { Phase } 1 \text { and have no } \\
\text { reaction. }\end{array}$ & $\begin{array}{l}\text { Touch the robot less } \\
\text { than } 2 \text { times }^{1} \text {. }\end{array}$ & $\begin{array}{l}\text { Stand up and do not demonstrate } \\
\text { any interest of playing with the } \\
\text { robot as shown by the mediator. }\end{array}$ \\
\hline $\begin{array}{l}\text { Expected level of } \\
\text { outcome }\end{array}$ & 0 & $\begin{array}{l}\text { Look at robot in the } \\
\text { Phase } 1 \text { and keep looking } \\
\text { at the monitor with no } \\
\text { interest. }\end{array}$ & $\begin{array}{l}\text { Touch the robot at least } \\
2 \text { times. }\end{array}$ & $\begin{array}{l}\text { Play with the robot, as shown by } \\
\text { the mediator, at least } 2 \text { times }^{2} \text {. }\end{array}$ \\
\hline $\begin{array}{l}\text { Greater than } \\
\text { expected outcome }\end{array}$ & +1 & $\begin{array}{l}\text { Look at the robot in the } \\
\text { Phase } 1 \text { and pay attention } \\
\text { to the monitor. }\end{array}$ & $\begin{array}{l}\text { Touch the robot more } \\
\text { than } 2 \text { times and pay } \\
\text { attention to its colours } \\
\text { and shape. }\end{array}$ & $\begin{array}{l}\text { Play with the robot, as shown by } \\
\text { the mediator, more than } 2 \text { times. }\end{array}$ \\
\hline $\begin{array}{l}\text { Most favourable } \\
\text { outcome }\end{array}$ & +2 & $\begin{array}{l}\text { Look at the robot in the } \\
\text { Phase } 1 \text { and show interest } \\
\text { in moving towards the } \\
\text { robot. }\end{array}$ & $\begin{array}{l}\text { Touch the robot more } \\
\text { than } 2 \text { times and play } \\
\text { with it. }\end{array}$ & $\begin{array}{l}\text { Play with the robot, as shown by } \\
\text { the mediator, more than } 4 \text { times. }\end{array}$ \\
\hline
\end{tabular}

${ }^{1}$ Considering the face and the arms are two regions visually attractive. ${ }^{2}$ Considering two movements of the robot: going towards the robot and going away from the robot. 
The self-presentation was crucial to help children feeling more comfortable and create an environment of positive interaction (fact that is not shown in any other paper as far as we know), since they had not seen the robot previously. Moreover, the robot helped the child-robot interaction (physical touching and eye gaze) and child-adult indirect interaction (imitate the mediator). Other interactions were also observed, such as verbal communication. Besides, the children with ASD of our study sang, walked, and gave their hands to the robot. This real interaction was never described in another work.

Specifically, in relation to the social abilities presented for the children with ASD during the interaction with MARIA, most of them (4 out of 5) interacted very well or moderately with the robot, in a similar way as the children of the control group, as shown in Figures 3-5. Only one child with ASD showed fear of the robot. In terms of similarity, the median values of the parameters: "look away the robot" and "imitate the mediator" were close between the ASD group and control group (Figure 5). The action of looking away from the robot observed in ASD children can be related to joint activity, since some of them looked to their parents, while they were watching the animations in Phase 1, showing interest on the videos. The same was noted in some children of the control group. Regarding the touching, the median values show the ASD group touched the robot more frequently.

In general, the results obtained with this study were satisfactory, because the social skills were stimulated in both groups, especially in the ASD children. Although these later have difficulties in eye gazing, touching and imitation, among other social skills (Cabibihan et al., 2013; Kim et al., 2013; Scassellati et al., 2012), the robot was able to stimulate them in a positive or moderate positive way in 4 out of 5 children, based on the answers to the questionnaire of the Likert scale (Figure 4). On the other hand, the GAS method, which evaluates the social goals, indicated that the children achieved the goals "better than expected," endorsing the positive child-robot interaction (Figure 5). Then, according to the results of this study, the goal of developing a robot to stimulate the social skills in ASD children was reached, as the robot can be used in repetitive way to improve the children's skills in each session.

Besides the analysis of the two essential social features, visual contact and touch (assessed in GAS), the tests were also performed in order to verify if the robot could be a mediator of interaction between the child and another person (in this case, the mediator/researcher), during the Phase 2. The first examples of social interaction were the children attending the mediator's commands to interact with the robot, and imitating the mediator (as evaluated in GAS). Moreover, we observed that the children did not avoid interaction with the robot when the researchers started interacting too, indicating the presence of shared engagement (another social feature). More specifically, both children and researchers walked and played with MARIA. Some children presented verbal communication (another social feature), saying the name of parts of MARIA body, and appointing the directions that the robot should move, as described in Table 2. Finally, a child with ASD held, spontaneously, the researcher's hands during the interaction with the robot (Table 2), i.e., a physical contact (another social feature that was stimulated by the robot).

During the sessions, in general, the ASD children performed extra social activities. In addition, a verbal communication was exhibited by a child in an occasional way, but never before detected, according to opinion of his grandmother (volunteer V3), described in Table 2. On the other hand, the children (4 out of 5 children) responded the mediator's commands frequently and non-verbal communications were observed, like gestures and pointing with hands and fingers.

The observational qualitative and quantitative data confirm that the ludic aspect helped the children with ASD to pay attention, along with looking to the robot and touching it. The robot plays the role of a mediator in a child-adult-robot interaction, where the child interacts indirectly with other human (one of the researchers). The design certainly improved the GAS and Likert scale scores, since the robot appearance is an important feature not to generate negative expectation or fear.

All this scenario of good tests is reflected by both robot behaviour and its aesthetics. Some studies, such as (Cabibihan et al., 2013; Giullian et al., 2010; Paron-Wildes, 2005), show that a robot to interact with children with ASD should follow some guidelines about style and colours. MARIA followed these suggestions and, in addition, had a self-presentation, which made the experiment a rich experience for the children. This was proven both by the metric scales and by observational data.

We believe that MARIA's structure contributed for the positive child-robot interaction. This structure is composed of an attractive, ludic, and colourful costume and has a similar height of the volunteer children, besides a multimedia system that displays animations (video and sounds). In addition, the mobile feature of the robot is also important to attract the children's attention, because ASD children usually are interested in objects that move (Cabibihan et al., 
2013; Michaud and Clavet, 2001). All this features of the robot caught the children's attention and curiosity, stimulating them to touch and play with the robot.

Although we consider the usability of the robot MARIA, there are some limitations in this work, such as the small sample number of volunteers, and the fact the robot still has to be remotely controlled. Due to the difficulty in finding children that met the inclusion and exclusion criteria, the experiments were conducted with five ASD children and five without ASD, in order to have both groups with the same number of volunteers. Other researches with ASD children interacting with robots, such as (Goodrich et al., 2012; Robins et al., 2004; Robins and Dautenhahn, 2014; Shamsuddin et al., 2012; Warren et al., 2015), also present number of volunteers similar to ours (or smaller) with $\mathrm{N}$ equals to $4,2,1$, 6 and 8 respectively.

As further steps of this research, the robot will be fully autonomous and some new interactions devices added, such as a voice system to allow the robot communicate with the child and an animated face, fulfilling the extra social skills remarked in this work. In addition, more sessions will be performed, with the new version of the robot. These new features are likely to make the children even more comfortable, which may lead to an even better interaction. The whole intention of creating a new robot style, including new devices to catch the children's attention, is to enhance the probability of interaction, both in terms of quantity and in terms of quality.

As a conclusion, we believe the robot MARIA, used in a repetitive way, can be a useful tool for enhancing the socialization skills of ASD children, since they reacted well to the robotic system. Moreover, new forms of interaction can be proposed in future works in order to stimulate further cognitive and emotional advancements of these children.

\section{Acknowledgements}

Authors acknowledge: (UFES/Brazil) for technical support; $\mathrm{CNPq} /$ Brazil (National Council of Technological and Scientific Development) and FAPES/Brazil (Support Foundation to Research and Innovation of Espirito Santo) for the financial support (numbers 458651/2013-3 and 67662536); AMAES, EMEF-UFES, the children's parents, caretakers, family and/or legal guardians and the volunteer children.

\section{References}

American Psychiatric Association. Diagnostic and statistical manual of mental disorders. 5th ed. Arlington: APA; 2013. http://dx.doi.org/10.1176/appi.books.9780890425596.744053.
Anzalone SM, Tilmont E, Boucenna S, Xavier J, Jouen AL, Bodeau N, Maharatna K, Chetouani M, Cohen D. How children with autism spectrum disorder behave and explore the 4-dimensional (spatial 3D + time) environment during a joint attention induction task with a robot. Research in Autism Spectrum Disorders. 2014; 8(7):814-26. http:// dx.doi.org/10.1016/j.rasd.2014.03.002.

Autism Grande Cause. [internet]. Le Chesnay; 2012 [cited 2016 Feb 13]. Available from: http://www.autismegrandecause2012.fr/

Autism Resource Centre. [internet]. Singapore; 2013 [cited 2016 Feb 13]. Available from: http://www.autism.org.sg/

Autism Society. [internet]. Maryland; 2016 [cited 2016 Feb 13]. Available from: http://www.autism-society.org/

Bartneck C, Kulic D, Croft E, Zoghbi S. Measurement instruments for the anthropomorphism, animacy, likeability, perceived intelligence, and perceived safety of robots. International Journal of Social Robotics. 2009; 1(1):71-81. http://dx.doi.org/10.1007/s12369-008-0001-3

Bekele ET, Lahiri U, Swanson AR, Crittendon JA, Warren ZE, Sarkar N. A step towards developing adaptive robotmediated intervention architecture (ARIA) for children with autism. IEEE Transactions on Neural Systems and Rehabilitation Engineering. 2013; 21(2):289-99. http:// dx.doi.org/10.1109/TNSRE.2012.2230188. PMid:23221831

Brasil. Ministério da Saúde. Diretrizes de atenção à reabilitação da pessoa com Transtornos do Espectro do Autismo (TEA). Brasília: MS; 2013.

Cabibihan JJ, Javed H, Ang M, Aljunied SM. Why robots? A survey on the roles and benefits of social robots in the therapy of children with autism. International Journal of Social Robotics. 2013; 5(4):593-618. http://dx.doi. org/10.1007/s12369-013-0202-2.

Centers for Disease Control and Prevention. Autism spectrum disorders: data and statistics [internet]. CDC; 2013 [cited 2016 Feb 13]. Available from: http://www.cdc.gov/ncbddd/ autism/data.html.

Costa S, Lehmann H, Dautenhahn K, Robins B, Soares F. Using a humanoid robot to elicit body awareness and appropriate physical interaction in children with autism. International Journal of Social Robotics. 2015; 7(2):265-78. http://dx.doi.org/10.1007/s12369-014-0250-2

Dautenhahn K. Roles and functions of robots in human society: implications from research in autism therapy. Robotica. 2003; 21(4):443-52. http://dx.doi.org/10.1017/ S0263574703004922.

Duquette A, Michaud F, Mercier H. Exploring the use of a mobile robot as an imitation agent with children with lowfunctioning autism. Autonomous Robots. 2008; 24(2):147-57. http://dx.doi.org/10.1007/s10514-007-9056-5

Elsabbagh M, Divan G, Koh YJ, Kim YS, Kauchali S, Marcín C, Montiel-Nava C, Patel V, Paula CS, Wang C, Yasamy MT, Fombonne E. Global prevalence of autism and other pervasive developmental disorders. Autism Research. 2012; 5(3):160-79. http://dx.doi.org/10.1002/ aur.239. PMid:22495912 
Fombonne E. Epidemiology of pervasive developmental disorders. Pediatric Research. 2009; 65(6):591-8. http://dx.doi. org/10.1203/PDR.0b013e31819e7203. PMid:19218885.

Giullian N, Ricks D, Atherton A, Colton M, Goodrich $\mathrm{M}$, Brinton B. Detailed requirements for robots in autism therapy. In: Conference Proceedings - IEEE International Conference on Systems, Man and Cybernetics; 10-13 Oct. 2010; Istanbul, Turkey. Istanbul: IEEE; 2010. p. 2595-602. http://dx.doi.org/10.1109/ICSMC.2010.5641908.

Goodrich MA, Colton M, Brinton B, Fujiki M, Atherton JA, Robinson L, Ricks D, Maxfield MH, Acerson A. Incorporating a robot into an autism therapy team. IEEE Intelligent Systems. 2012; 27(2):52-9. http://dx.doi.org/10.1109/MIS.2012.40.

Honda H, Shimizu Y, Rutter M. No effect of MMR withdrawal on the incidence of autism: a total population study. Journal of Child Psychology and Psychiatry, and Allied Disciplines. 2005; 46(6):572-9. http://dx.doi.org/10.1111/j.14697610.2005.01425.x. PMid:15877763.

Ingersoll B. Brief report: effect of a focused imitation intervention on social functioning in children with autism. Journal of Autism and Developmental Disorders. 2012; 42(8):1768-73. http://dx.doi.org/10.1007/s10803-011-14236. PMid:22146934.

Kim ES, Berkovits LD, Bernier EP, Leyzberg D, Shic F, Paul $\mathrm{R}$, Scassellati B. Social robots as embedded reinforcers of social behavior in children with autism. Journal of Autism and Developmental Disorders. 2013; 43(5):1038-49. http:// dx.doi.org/10.1007/s10803-012-1645-2. PMid:23111617.

Kiresuk TJ, Sherman RE. Goal attainment scaling: a general method for evaluating comprehensive community mental health programs. Community Mental Health Journal. 1968; 4(6):443-53. http://dx.doi.org/10.1007/BF01530764. PMid:24185570.

Klin A. Autismo e síndrome de Asperger: uma visão geral. Revista Brasileira de Psiquiatria (Sao Paulo, Brazil). 2006; 28(Suppl. 1):3-11. http://dx.doi.org/10.1590/S151644462006000500002 .

Knapp EL. Nonverbal communication in human interaction. California: Holt, Rinehart and Winston; 1978.

Kozima H, Michalowski MP, Nakagawa C. Keepon: a playful robot for research, therapy, and entertainment. International Journal of Social Robotics. 2009; 1(1):3-18. http://dx.doi. org/10.1007/s12369-008-0009-8.

Krasny-Pacini A, Hiebel J, Pauly F, Godon S, Chevignard M. Goal attainment scaling in rehabilitation: a literaturebased update. annals of physical and rehabilitation medicine. Elsevier Masson SAS. 2013; 56(3):212-30. http://dx.doi. org/10.1016/j.rehab.2013.02.002. PMid: 23562111.

Lamas WQ, Tani HM, Sousa JSS, Reis LOM. An oximetrybased method for monitoring reactions of autistic subjects under music auditions. Revista Brasileira de Engenharia Biomédica. 2009; 25(3):175-84. http://dx.doi.org/10.4322/ rbeb.2012.074

Leventhal BL, Koh Y, Ph D, Laska E, Ph D, Lim E, Kim S, Kim Y, Lee H, Song D, Grinker RR, Ph D. Prevalence of Autism Spectrum Disorders in a Total Population Sample Young. The American Journal of Psychiatry. 2013; 170(904-
912):689. http://dx.doi.org/10.1176/appi.ajp.2011.10101532. PMid: 21558103.

Lord C, Cook EH, Leventhal BL, Amaral DG. Autism spectrum disorders. Neuron. 2000; 28(2):355-63. http:// dx.doi.org/10.1016/S0896-6273(00)00115-X. PMid:11144346.

Michaud F, Clavet A. RoboToy contest: designing mobile robotic toys for autistic children. Artificial Intelligence. $2001 ; 1-4$

Michaud F, Duquette A, Nadeau I. Characteristics of mobile robotics toys for children with pervasive developmental disorders. In: Proceedings of the IEEE International Conference on Systems, Man and Cybernetics; 5-8 Oct. 2003; Washington, USA. Washington, D.C.: IEEE; 2003. p. 2938-43. http://dx.doi.org/10.1109/ICSMC.2003.1244338.

Norris S, Pare JR, Starky S. Childhood Autism in Canada: some issues relating to behavioural intervention. Canada Library of Parliament; 2006.

Paron-Wildes AJ. Sensory stimulation and Autistic children. Implications. 2005; 06(04):1-5.

Robins B, Dautenhahn K, te Boekhorst R, Billard A. Effects of repeated exposure to a humanoid robot on children with autism: designing a more inclusive world. London: Springer; 2004. p. 225-36.

Robins B, Dautenhahn K, Dubowski J. Does appearance matter in the interaction of children with autism with a humanoid robot? Interaction Studies. 2006;7(3):509-42.

Robins B, Dautenhahn K. Tactile interactions with a humanoid robot: novel play scenario implementations with children with autism. International Journal of Social Robotics. 2014; 6(3):397-415. http://dx.doi.org/10.1007/s12369-014-0228-0.

Rossignol DA, Frye RE. Mitochondrial dysfunction in autism spectrum disorders: a systematic review and metaanalysis. Molecular psychiatry. Nature Publishing Group. 2012; 17(3):290-314. http://dx.doi.org/10.1038/mp.2010.136. PMid: 21263444.

Rutter M. Aetiology of autism: findings and questions. Journal of Intellectual Disability Research. 2005; 49(4):2318. http://dx.doi.org/10.1111/j.1365-2788.2005.00676.x. PMid:15816809.

Salter T, Dautenhahn K, Te Boekhorst R. Learning about natural human-robot interaction styles. Robotics and Autonomous Systems. 2006; 54(2):127-34. http://dx.doi. org/10.1016/j.robot.2005.09.022.

Scassellati B, Admoni H, Matarić M. Robots for use in autism research. Annual Review of Biomedical Engineering. 2012; 14(1):275-94. http://dx.doi.org/10.1146/annurevbioeng-071811-150036. PMid:22577778.

Shamsuddin S, Yussof H, Ismail LI, Mohamed S, Hanapiah FA, Zahari NI. Initial response in HRI: a case study on evaluation of child with autism spectrum disorders interacting with a humanoid robot NAO. Procedia Engineering. 2012; 41:1448-55. http://dx.doi.org/10.1016/j.proeng.2012.07.334.

Simut RE, Vanderfaeillie J, Peca A, Van de Perre G, Vanderborght B. Children with autism spectrum disorders make a fruit salad with probo, the social robot: An interaction study. Journal of Autism and Developmental Disorders. 
2015; 46(1):113-26. http://dx.doi.org/10.1007/s10803-0152556-9. PMid: 26304031.

The National Autistic Society. Communicating and interacting [internet]. London: The National Autistic Society; 2015 [cited 2016 Feb 16]. Available from: www.autism.org.uk/ communicate

Turner-Stokes L. Goal attainment scaling (GAS) in rehabilitation: a practical guide. Clinical Rehabilitation. 2009; 23(4):362-70. http://dx.doi.org/10.1177/0269215508101742. PMid:19179355.

Valadao CT. Social interaction with autistic child using robot [internet]. Youtube; 2016 [cited 2016 Feb 16]. Available from: https://www.youtube.com/watch?v=mihryD_mzmQ
Wada K, Shibata T, Saito T, Tanie K. Effects of robot-assisted activity for elderly people and nurses at a day service center. Proceedings of the IEEE. 2004; 92(11): 1780-8. http:// dx.doi.org/10.1109/JPROC.2004.835378.

Wainer J, Robins B, Amirabdollahian F, Dautenhahn K. Using the humanoid robot KASPAR to autonomously play triadic games and facilitate collaborative play among children with autism. IEEE Transactions on Autonomous Mental Development. 2014; 6(3):183-99. http://dx.doi. org/10.1109/TAMD.2014.2303116.

Warren Z, Zheng Z, Das S, Young EM, Swanson A, WeitlaufA, Sarkar N. Brief Report: development of a robotic intervention platform for young children with ASD. Journal of Autism and Developmental Disorders. 2015; 45(12):3870-6. http:// dx.doi.org/10.1007/s10803-014-2334-0. PMid: 25503680.

\section{Authors}

Carlos Torturella Valadão ${ }^{1 *}$, Christiane Goulart ${ }^{1}$, Hamilton Rivera $^{1}$, Eliete Caldeira ${ }^{1}$, Teodiano Freire Bastos Filho $^{1}$, Anselmo Frizera-Neto ${ }^{1}$, Ricardo Carelli ${ }^{2}$

${ }^{1}$ Programa de Pós-graduação em Engenharia Elétrica, Laboratório de Automação Inteligente, Universidade Federal de Espírito Santo - UFES, Avenida Fernando Ferrari, 514, Goiabeiras, CEP 29075-910, Vitória, ES, Brazil.

\footnotetext{
${ }^{2}$ Universidade Nacional de San Juan, San Juan, Argentina.
} 